\title{
Searching for road deformations using mobile laser scanning
}

\author{
Jakub Szulwic ${ }^{1, *}$, and Pawet Tysiąc ${ }^{1}$ \\ ${ }^{1}$ Gdansk University of Technology, Faculty of Civil and Environmental Engineering, Poland
}

\begin{abstract}
Millions of people use roads every day all over the world. Roads, like many other structures, have an estimated durability. In Poland a lot of the roads were built at the turn of the $20^{\text {th }}$ and $21^{\text {st }} \mathrm{c}$., especially for light cars. Many of these roads carry traffic and heavy goods vehicles which were not predicted when the traffic was first estimated. It creates a lot of problems with technical conditions and the infrastructure must be improved. Treatments can be problematic, because restoring the original properties of the road requires workers to restrict traffic as cars may cause a lot of damage to the construction. In the article the authors present a method for estimating the condition of a road using the MLS (Mobile Laser Scanning) measurement technique. It is based on a mobile platform and equipped with the Riegl VMZ-400 scanning system. Post-processing of the data constrain to extract the scan lines and road's condition analysis in addition to estimate its parameters. In conclusion, the authors present the advantages and disadvantages of Mobile Laser Scanning in addition to the paths. Moreover, tell the possibility of the factors determine which describe the security level of the roads.
\end{abstract}

\section{Introduction}

Millions of people use roads every day all over the world. Roads, like many other structures, have an estimated durability. In Poland a lot of the roads were built at the turn of the $20^{\text {th }}$ and $21^{\text {st }}$ c., especially for light cars [1]. Many of these roads carry traffic and heavy goods vehicles which were not predicted when the traffic was first estimated. It creates a lot of problems with technical conditions and the infrastructure must be improved. Treatments can be problematic, because restoring the original properties of the road requires workers to restrict traffic as cars may cause a lot of damage to the construction.

Another issue other than repairing roads, are traffic accidents. Most of them are caused by incompetence of the drivers who exceed speed limits. And even when the speed limit is respected by the drivers, the technical condition of the roads combined with bad atmospheric conditions could cause very problematic situations. To reduce accidents, it is very important to implement the safety policy proposed by the transportation office. To create a safety plan a lot of factors have to be taken into consideration such as the environment. Noise pollution in cities is a problem which was created by roads. The solution is to predict the level of traffic noise. It is possible to study the average level of traffic over a period of time (for example traffic volume or average traffic speed) [2]. Because the technical condition of roads is so important, we must remember that roads behave dynamically. When developing a proper

\footnotetext{
${ }^{*}$ Corresponding author: szulwic@pg.gda.pl
} 
safety plan and action plans, the condition of the roads cannot be ignored. Apart from environmental factors, an inventory has to be conducted. It is possible to measure the road condition using manual or automatic techniques. Manual techniques are very time consuming, so the best solution is to use innovative measuring techniques which are very efficient and accurate for detecting defects [3]. In this study mobile laser scanning was used. The dataset was acquired by the Riegl VMZ-400 scanning system. The workflow of processing the data was designed to acquire the data, post-process and analyse them to create a defect map, where cracks in the road were detected.

\section{Data acquisition and data processing}

To acquire the spatial data, the Riegl VMZ-400 hybrid system was used. It means that the VZ-400 scanner could be used successfully as the terrestrial and the mobile laser scanner. It helps to gather information about the entire scanned object, does not leave any space without points which is a significant assumption during planning. It is especially important in searching for deformations because all of the details of the object have to be moved to the next steps of processing the data. It is commonly known that the car cannot drive into every area so using terrestrial laser scanning as a supplement is a good solution. In circumstances, where the global accuracy should be very high, the TLS could be used as the reference [4] for mobile data.

The mobile scanner is placed on a platform. Using IMU (Inertial Measurement Unit) and a GNSS receiver the scanning system is created assisted with the DMI (Distance Measurement Indicator). To adjust all the components into one system, offsets of the device's centre have to be estimated with very high accuracy. The Riegl VMZ-400 has two mounting configurations: vertical and horizontal.

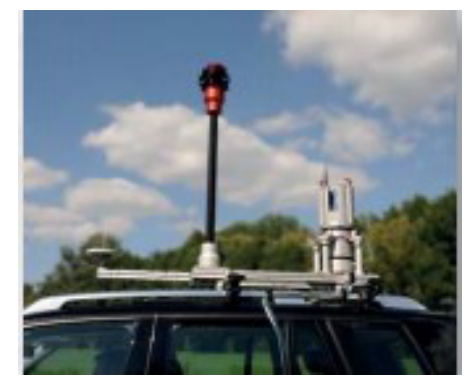

Fig. 1. Riegl VMZ-400 Vertical mounting [5].

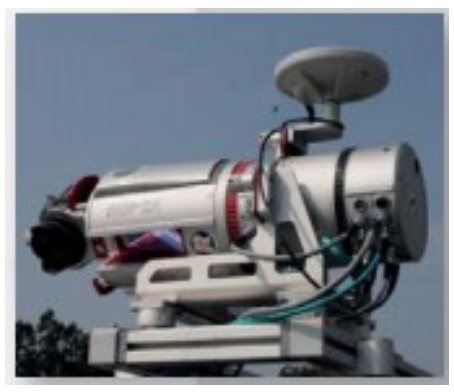

Fig. 2. Riegl VMZ-400 Horizontal mounting [5].

To prepare a proper calibration providing correct measurements, the correlations between the devices have to be evaluated. The evaluation is based on the direction of the axis of the system (X-axis should be turned into the driving direction, $\mathrm{Z}$ - on the ground, Y- on the right 
of the platform) according to the right hand rule. The values and directions of the axis from the devices are contained in calibration papers provided by the producer. Additional measurements have to be done, according to the DMI integration with the system. With that operation, the global position of the scanner is estimated during the mission. It is crucial when the user changes the configuration frequently (e.g. vertical configuration is better for gathering information about buildings, while horizontal about roads). [6]

According to data acquisition, the values of pitch (rotation around side-to-side-axis), roll (rotation around the front-to-back-axis) and yaw (rotation around the $\mathrm{Z}$ axis) were established. The values of rotations are presented in Fig. 3. The accuracy of these angles depends on the proper static and dynamic alignment. The static alignment is based on 5 minutes of spatial data gathering about the position of the unit through the GNSS receiver, while the dynamic alignment consists of alternating acceleration and deceleration of the vehicle before data registration. In the project described in this paper, a proper alignment was crucial because the car was driving at $10 \mathrm{~km} / \mathrm{h}$ and at that speed the estimation accuracy of the rotation values decreased. It is possible to constrain the rapidity of the drop by repeatedly executing the dynamic alignment [7], [8]. As you can see in Fig. 3, the roll angular values change from -96 to -84 degrees, pitch from 41 to 50 degrees and yaw from 50 to 350 degrees during the time between 294000 seconds to 299000 seconds. It has to be mentioned that on the right side of the picture there are charts presenting the changing values of the angles in reference to $\mathrm{dB}$ and $\mathrm{Hz}$ values.

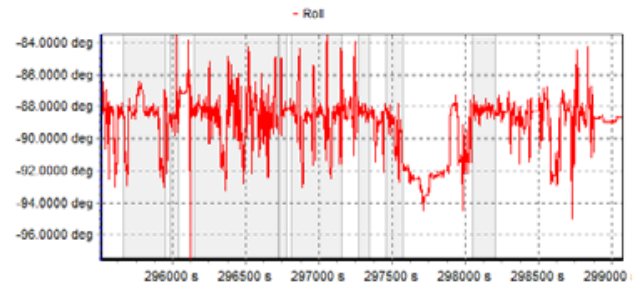

- Pren

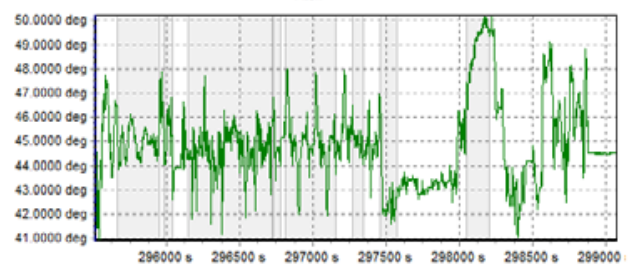

Yaw

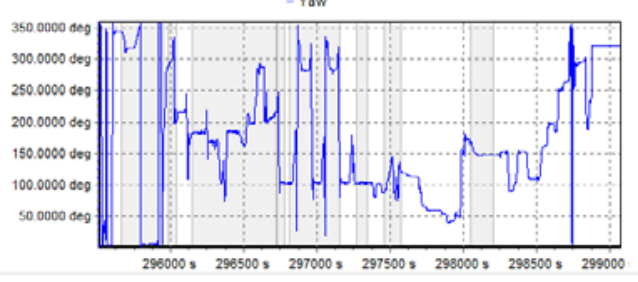

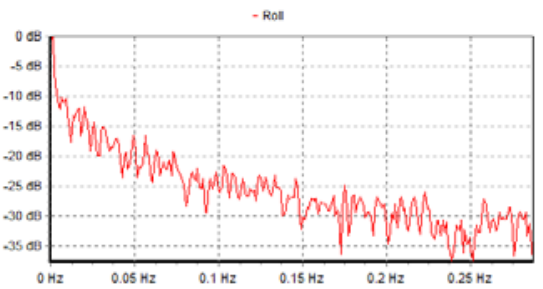
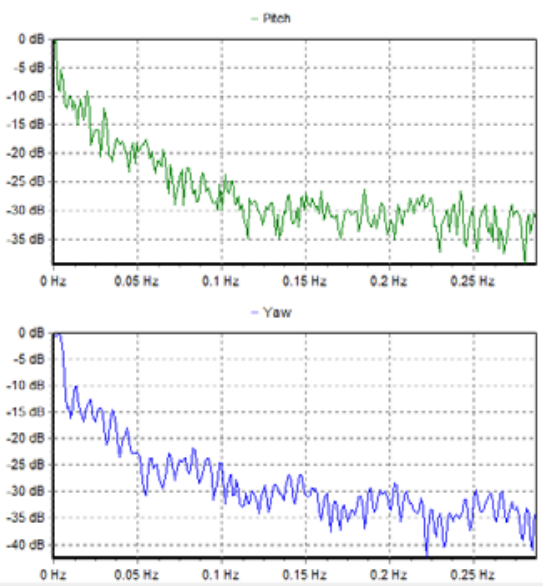

Fig. 3. Roll, Pitch, Yaw values.

The evaluation of the collected data was made after the trajectory alignment, based on GNSS reference network stations (ASG- EUPOS), but in this paper the global accuracy of the data was not that important as the accuracy of the deformations (e.g. cracks), their size and precision of the points. The result of the scanned data is presented in Fig. 4. It has to be mentioned that, when the accuracy is important, not only the reference network should be created but also the GPS positioning should be evaluated [9], [10]. 


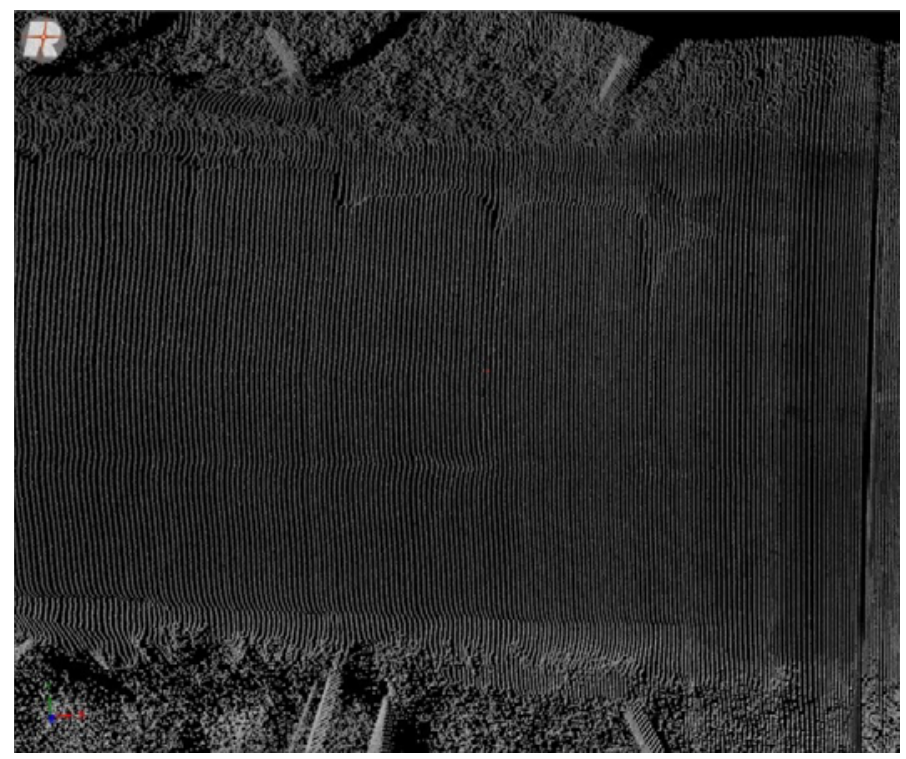

Fig. 4. The result of road scanning using Riegl VMZ-400 Mobile System.

After evaluation of the data, the filtering step was made. The terrain filter used is based on a hierarchic model of data where numerous estimations were made. For each it was established if the point is located on the plane described as the ground.

The algorithm starts with a level represented by the X/Y plane of the project coordinate system and estimates robust planes in the next stages. The points which were marked during the next stages, are marked as not belonging to the ground. With that operation, it is possible to remove noise from the cars which interrupted the measurements, from vegetation if any and noise which cannot be defined.

The last preparation before searching for cracks and ruts is to triangulate the data. It is a semi-automatic process which creates surfaces by connecting the points with triangles. The results of processing operation of the point cloud are presented in Fig. 5.

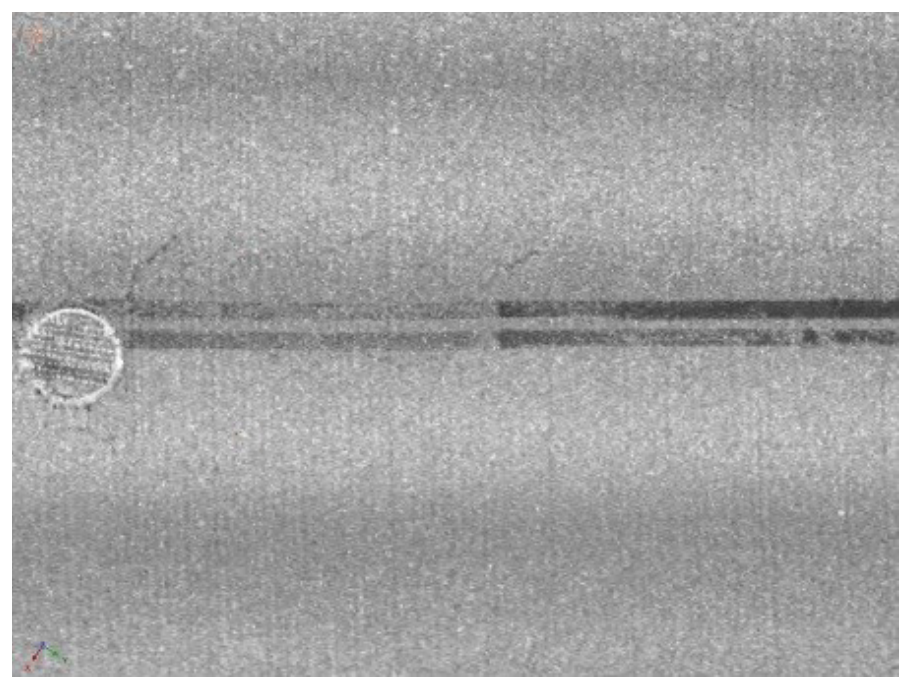

Fig. 5. The result of processed data. 


\section{Data analysis}

The analysis of the data was based on the power of the reflected laser beam from the surface. A ray of the laser penetrated cracks on the roads because of a small diameter. The reflectance depends on the material and slope. With that property, it is possible to find cracks and ruts [13], based on material properties [14].

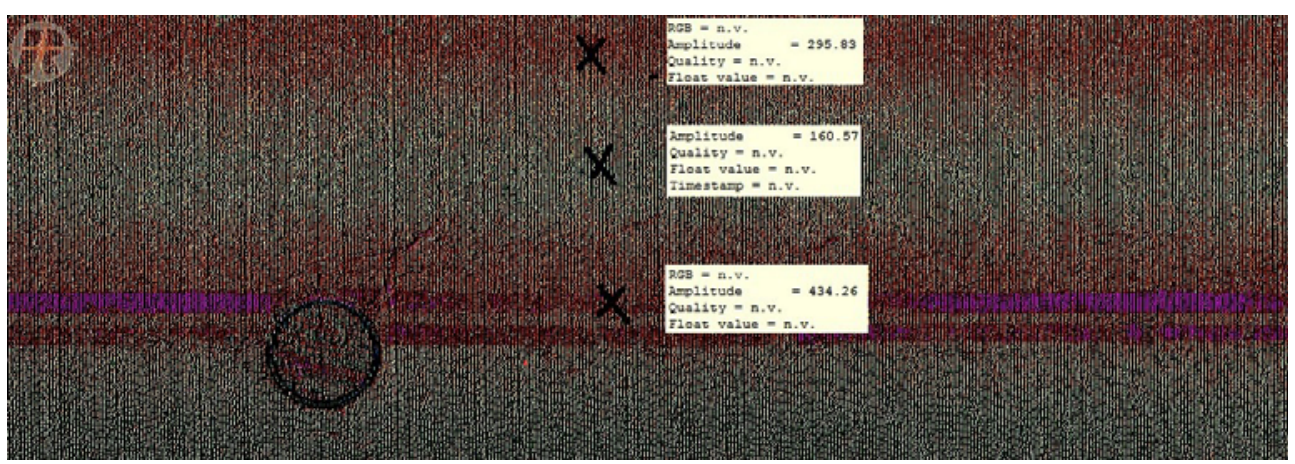

Fig. 6. Amplitude differences.

To exactly indicate places with cracks and ruts, the values of the amplitude must be estimated which are not affected by the traffic [15]. Fig. 6 shows the representation of the amplitude's values of terrain not affected, affected by the weight of traffic (based on that property the rut paths could be estimates) and cracks in the roads. What is interesting is that lines on the roads have the same amplitude as cracks. With that assumption, it is crucial to classify the road as the reflectivity function of the laser beam.

\section{Experiment results}

The main goal of this paper was to propose an application for searching for cracks in the road using mobile laser scanning. During the analysis of the data, the authors found, that based on the amplitude searching method there is a possibility to indicate ruts or road infrastructure such as manholes. The results of this classification are presented in Fig. 7

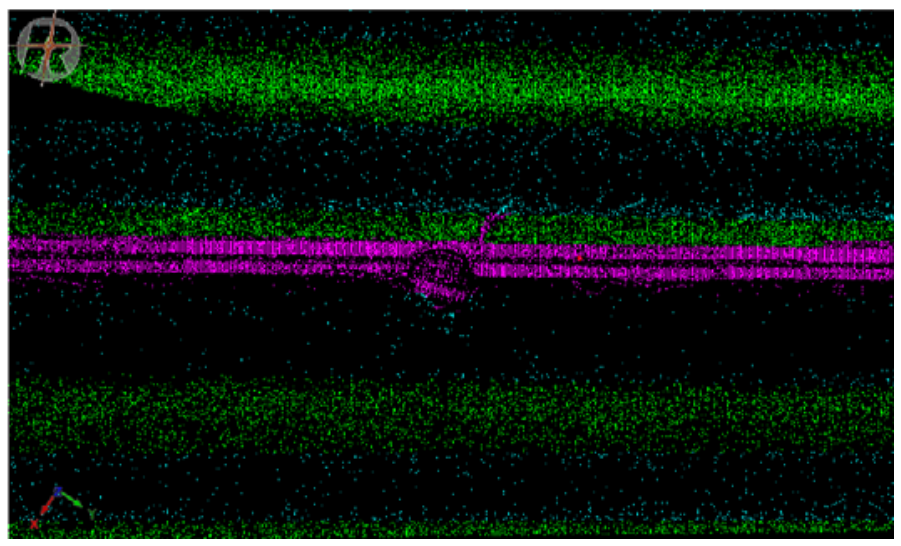

Fig. 6. Road classification (green - place not affected by the traffic, aqua- ruts, purple- line and cracks). 


\section{Conclusions}

Mobile laser scanning (MLS) could be very useful for searching for road deformations. During the experiment the authors showed that the application could provide a valuable proof of the technical condition. A full analysis of the roads (for example to determine the safety factor of the paths) needs to combine geodesy measurement methods (like photogrammetry methods which are terrestrial and mobile laser scanning). Only by applying a complex and professional approach to the problem (which is estimating the roads' condition) can we indicate the technical and organizational threats and help to improve safety for all road users $[13,17-19]$. It has to be mentioned that if the density of the point cloud is too little to analyse, it is possible to use a high resolution point cloud collected using a different method than laser scanning [20] or by using different methods for monitoring [21].

\section{References}

1. W. Kozłowski, Innovative Technological Solutions in Terms of Realizations Partial Renovation of Bituminous Roads Using SPRIDER, Procedia Eng. 161 pp. 503-510 (2016). doi:10.1016/j.proeng.2016.08.676

2. F. Li, S.S. Liao, M. Cai, A new probability statistical model for traffic noise prediction on free flow roads and control flow roads, Transp. Res. Part D Transp. Environ. 49 pp. 313-322 (2016). doi:10.1016/j.trd.2016.10.019

3. D. Zai, Y. Guo, J. Li, H. Luo, Y. Lin, Y. Sun, P. Huang, C. Wang, 3D road surface extraction from mobile laser scanning point clouds, in: 2016 IEEE Int. Geosci. Remote Sens. Symp., pp. 1595-1598 (IEEE, 2016). doi:10.1109/IGARSS.2016.7729407

4. P. Tysiac, A. Wojtowicz, J. Szulwic, Coastal Cliffs Monitoring and Prediction of Displacements Using Terrestial Laser Scanning, in: 2016 Balt. Geod. Congr. (BGC Geomatics), pp. 61-66 (IEEE, 2016). doi:10.1109/BGC.Geomatics.2016.20

5. Riegl VMZ-400 Infosheet, www.riegl.com, (n.d.)

6. A. Kukko, H. Kaartinen, J. Hyyppä, Y. Chen, Multiplatform Mobile Laser Scanning: Usability and Performance, Sensors. 12 pp. 11712-11733 (2012). doi:10.3390/s120911712

7. A. Janowski, J. Szulwic, P. Tysiąc, A. Wojtowicz, Airborne and Mobile Laser Scanning in Measurements of Sea Cliffs on the Southern Baltic, in: 15th Int. Multidiscip. Sci. GeoConference SGEM 2015, pp. 17-24 (2015)

8. J. Szulwic, P. Burdziakowski, A. Janowski, M. Przyborski, P. Tysiąc, A. Wojtowicz, A. Kholodkov, K. Matysik, M. Matysik, Maritime Laser Scanning as the Source for Spatial Data, Polish Marit. Res. 22 (2015). doi:10.1515/pomr-2015-0064

9. A. Janowski, A. Nowak, M. Przyborski, J. Szulwic, Mobile Indicators in GIS and GPS Positioning Accuracy in Cities, Lect. Notes Comput. Sci. pp. 309-318 (2014). doi:10.1007/978-3-319-08729-0_31

10. T. Nuttens, A. De Wulf, G. Deruyter, C. Stal, H. De Backer, K. Schotte, Deformation monitoring with terrestrial laser scanning: Measurement and processing optimization through experience, in: Int. Multidiscip. Sci. GeoConference-SGEM, pp. 707-714 (Albena, 2012). doi:10.5593/SGEM2012/S07.V2006

11. J. Żukowska, Regional Observatory as a Part of Road Safety Information System, 11th Int. Conf. Transp. Syst. Telemat. (TST 2011). 239 pp. 409-416 (2011). doi:10.1007/978-3-642-24660-9_47

12. R. Bergel-Hayat, J. Żukowska, Road Safety Trends at National Level in Europe: A 
Review of Time-series Analysis Performed during the Period 2000-12, Transp. Rev. 35 pp. 650-671 (2015). doi:10.1080/01441647.2015.1030005

13. A. Janowski, K. Nagrodzka-Godycka, J. Szulwic, P. Ziolkowski, Remote sensing and photogrammetry techniques in diagnostics of concrete structures, Comput. Concr. 18 pp. 405-420 (2016). doi:10.12989/cac.2016.18.3.405

14. C. Suchocki, J. Katzer, An example of harnessing Terrestrial Laser Scanner for remote sensing of saturation of chosen building materials, Constr. Build. Mater. 122 pp. 400 405 (2016). doi:10.1016/j.conbuildmat.2016.06.091

15. K. Bobkowska, A. Inglot, M. Mikusova, P. Tysi?c, Implementation of Spatial Information for Monitoring and Analysis of the Area Around the Port Using Laser Scanning Techniques, Polish Marit. Res. 24 pp. 10-15 (2017). doi:10.1515/pomr-20170015

16. S. Mikrut, P. Kohut, K. Pyka, R. Tokarczyk, T. Barszcz, T. Uhl, Mobile Laser Scanning Systems for Measuring the Clearance Gauge of Railways: State of Play, Testing and Outlook, Sensors. 16 pp. 683 (2016). doi:10.3390/s16050683

17. K. Jamroz, W. Kustra, M. Budzyński, J. Żukowska, Pedestrian Protection, Speed Enforcement and Road Network Structure the Key Action for Implementing Poland's Vision Zero, Transp. Res. Procedia. 14 pp. 3905-3914 (2016). doi:10.1016/j.trpro.2016.05.479

18. M. Budzyński, K. Jamroz, J. Pyrchla, W. Kustra, K. Pyrchla, Identifying the Effects of Selected Road and Roadside Parameters on Road Safety Using Geodetic Techniques, in: 2016 Balt. Geod. Congr. (BGC Geomatics), pp. 154-158 (IEEE, 2016). doi:10.1109/BGC.Geomatics.2016.35

19. B. Hejmanowska, W. Kaminski, M. Przyborski, K. Pyka, J. Pyrchla, Modern remote sensing and the challenges facing education systems in terms of its teaching, in: 7th Int. Conf. Educ. New Learn. Technol., pp. 6549-6558 (IATED, Barcelona, 2015)

20. K. Bobkowska, A. Janowski, M. Przyborski, J. Szulwic, Analysis of High Resolution Clouds of Points as a Source of Biometric Data, in: 2016 Balt. Geod. Congr. (BGC Geomatics), pp. 15-21 (IEEE, 2016). doi:10.1109/BGC.Geomatics.2016.12

21. K. Michalowska, E. Glowienka, A. Pekala, Spatial-temporal detection of changes on the southern coast of the Baltic Sea based on multitemporal aerial photographs, ISPRS - Int. Arch. Photogramm. Remote Sens. Spat. Inf. Sci. XLI-B2 pp. 49-53 (2016). doi:10.5194/isprsarchives-XLI-B2-49-2016 